\title{
ATIVIDADE DO NEONICOTINOIDE TIAMETOXAM SOBRE Musca domestica (LINNAEUS, 1758) (DIPTERA, MUSCIDAE)
}

\author{
Pedro Ivan Fazio Junior, ${ }^{1}$ Vanessa Paulino da Cruz Vieira, ${ }^{2}$ Thaís Ribeiro Correia, ${ }^{3}$ Fabio Barbour Scott ${ }^{4}$ \\ e Isabella Vilhena Freire Martins ${ }^{5}$
1. Discente de Mestrado do Curso de Pós-Graduação em Ciências Veterinárias do Departamento de Parasitologia Animal (DPA), Instituto de Veteriná- ria (IV), Universidade Federal Rural do Rio de Janeiro (UFRRJ)
2. Discente de Doutorado do Curso de Pós-Graduação em Ciências Veterinárias do DPA, IV, UFRRJ
3. Discente de Pós-Doutorado do DPA, IV, UFRRJ.
4- Professor adjunto do DPA, IV, UFRRJ \\ 5. Professora adjunto do Departamento de Medicina Veterinária (DMV) do Centro de Ciências Agrárias da Universidade Federal do Espírito Santo (CCA-UFES).
}

\section{RESUMO}

A partir de ensaios in vitro, em ambiente controlado e a campo, foi avaliada a atividade do inseticida tiametoxam em populações de Musca domestica provenientes da colônia do Laboratório de Doenças Parasitárias do Departamento de Epidemiologia e Saúde Pública da Universidade Federal Rural do Rio de Janeiro e do aterro sanitário do Município de Seropédica, RJ. Para a técnica in vitro o ativo utilizado foi previamente diluído em acetona, obtendo-se as concentrações de $5 ; 7,5 ; 10 ; 12,5 ; 15 ; 17,5 ; 20 ; 22,5$; $25 ; 27,5$ e $30 \mathrm{mg} / \mathrm{ml}$. Em seguida, discos de papel-filtro foram impregnados com $1 \mathrm{ml}$ de cada uma dessas diluições e realizaram-se testes com estas em moscas adultas acondicionadas em placas de Petri, sendo que os discos do grupo-controle foram impregnados apenas com acetona. Para técnica em ambiente controlado e em nível de campo, empregaram-se iscas com o ativo e placebo para o grupo-controle. O valor calculado da dose letal $50\left(\mathrm{DL}_{50}\right)$, utilizando-se a técnica in vitro, para tiametoxam em $M$. domestica foi de $0,2612 \mathrm{mg} / \mathrm{cm}^{2}$. A eficácia das iscas com tiamethoxan no ensaio em ambiente controlado e em nível de campo foi de 94,06 $\%$ e $98,09 \%$, respectivamente.

PALAVRAS-CHAVES: Iscas, Musca domestica, neonicotinoides, tiametoxam

\section{ABSTRACT}

\section{ACTIVITY OF NEONICOTINOID THIAMETOXAM ON Musca domestica (LINNAEUS, 1758) (DIPTERA, MUSCIDAE)}

The activity of the insecticide thiamethoxam on populations of Musca domestica was assessed through in vitro tests, controlled environment and field conditions. The flies were gathered from a colony maintained by the Laboratory of Parasitic Diseases, Department of Epidemiology and Public Health, Universidade Federal Rural do Rio de Janeiro, and from the landfill of the city of Seropédica-RJ, Brazil. Regarding the in vitro assay, thiamethoxan was previously diluted in acetone, resulting in concentrations of 5, $7.5,10,12.5,15,17.5,20,22.5,25,27,5$ and $30 \mathrm{mg} / \mathrm{ml}$. Then, filter paper discs were impregnated with $1 \mathrm{ml}$ of each of these dilutions. Thus, the test was conducted with adult flies maintained in Petri dishes. For the controlled environment and field conditions, trial baits were used with the active or a placebo (control group). The lethal concentration $50\left(\mathrm{LC}_{50}\right)$ of thiamethoxam on $M$. domestica found in the in vitro assay was $0.2612 \mathrm{mg} / \mathrm{cm}^{2}$. The efficacy of thiamethoxan baits on the controlled environment and field conditions trials was $94.06 \%$ and $98.09 \%$, respectively.

KEYWORDS: Baits, Musca domestica, neonicotinoids, thiamethoxam. 


\section{INTRODUÇÃO}

A espécie Musca domestica (Linnaeus, 1758), conhecida mundialmente como mosca doméstica, é um inseto cosmopolita e está em associação muito estreita com o homem e seu alimento, bebidas e lixo. Pelo seu hábito de regurgitar e depositar suas fezes no alimento, ela está relacionada com a transmissão de diversas doenças (HEWITT, 1914). Dentre elas são citados, na literatura, a febre tifoide, o cólera, o tracoma, lepra, conjutivites, o vírus da poliomielite, protozooses tais como Giardia duodenalis e Entamoeba coli (FREITAS et al., 1978; FOEDAR, 2001). Atua também como hospedeiro intermediário de alguns endoparasitos como Habronema muscae e Draschia megastoma nos equinos (COLLOBERT-LAUGIER, 2000), Raillietina sp. nas aves (HORSFALL, 1938) e como vetor forético de ovos de Dermatobia hominis (RIBEIRO, 1985).

Em função de sua importância, diversas medidas de controle têm sido implantadas, sendo o controle químico, através de formulações de inseticidas, o mais utilizado (NEVES \& NOGUEIRA, 1996). O controle nesta espécie constitui um grande problema em saúde pública, principalmente pela elevada resistência aos inseticidas químicos (CHAPMAN et al., 1993).

Os neonicotinoides são amplamente utilizados no controle de pragas de importância na agricultura (KAGABU, 1997). Estes apresentam uma boa atividade contra populações de pragas resistentes a outras classes de inseticidas como os organofosforados, os carbamatos, os piretroides, e muitas outras classes de compostos (NAUEN et al., 2003). Os neonicotinoides recebem essa denominação por se ligarem agonisticamente aos receptores nicotínicos pós-sinápticos de acetilcolina, afetando as sinapses no sistema nervoso central dos insetos (KAGABU, 1997). Eles representam uma classe promissora de inseticidas com excelentes propriedades químicas e biológicas (WAKITA et al., 2005). A segurança e a eficácia dos neonicotinoides têm sido atribuídas, em parte, à alta seletividade desses compostos pelos receptores nicotínicos de acetilcolina dos insetos quando comparados aos dos mamíferos (TOMIZAWA \& CASIDA, 2003).

Recentemente, KIRIYAMA (2002) realizou os primeiros estudos com o dinotefuran, em $M$. domesti$c a$, apresentando resultados eficazes no controle quí- mico além de ser uma forma auxiliar para o controle desses insetos resistentes a diferentes grupamentos químicos.

Os estudos envolvendo a ação do tiametoxam sobre $M$. domestica são escassos. No entanto, KRISTENSEN \& JESPERSEN (2008), em seus estudos, obtiveram a dose letal $50\left(\mathrm{DL}_{50}\right)$ do tiametoxam. VANHERK et al. (2008), ao empregarem esse inseticida no controle do coleóptero Agriotes obscurus, também obtiveram o valor da $\mathrm{DL}_{50}$.

O presente trabalho teve por objetivo avaliar a eficácia in vitro de diferentes concentrações de tiametoxam no controle de adultos de $M$. domestica, calcular a dose letal 50 a partir dos resultados obtidos no teste in vitro, e avaliar uma formulação de tiametoxam na apresentação de isca mosquicida em ambiente controlado e em nível de campo.

\section{MATERIAL E MÉTODOS}

A manutenção da colônia de $M$. domestica, o teste in vitro e os testes em ambiente controlados foram realizados no Laboratório de Quimioterapia Experimental em Parasitologia Veterinária (LQEPV), do Departamento de Parasitologia Animal (DPA), Instituto de Veterinária (IV), da Universidade Federal Rural do Rio de Janeiro (UFRRJ). Realizaram-se os testes em nível de campo no aterro sanitário do Município de Seropédica, RJ.

Adquiriram-se exemplares de $M$. domestica no Laboratório de Epidemiologia e Saúde Pública (DESP), (IV) da UFRRJ. As moscas foram mantidas no LQEPV em gaiolas medindo 28,5 cm de altura, 27,5 $\mathrm{cm}$ de largura e $32 \mathrm{~cm}$ de profundidade. A dieta para a manutenção de adultos foi a base de uma mistura contendo leite em pó e açúcar na proporção de 1:1, disponibilizada no interior da gaiola, além de água, embebida em algodão em placas de Petri, colocada diariamente no interior da gaiola. Como substrato de oviposição e dieta para as larvas utilizou-se uma mistura de ração de coelho e farelo de trigo na proporção de 1:1 umedecidas com água, distribuída em recipientes de plástico e alocada diariamente no interior da gaiola para obtenção de novas posturas. Após 24 horas, os recipientes foram retirados das gaiolas e transferidos para o interior de uma estufa climatizada com demanda bioquímica de oxigênio com temperatura constante de $27 \pm 1{ }^{\circ} \mathrm{C}$ e umidade relativa de $80 \pm 10 \%$. Após a 
emergência dos adultos, colocaram-se os recipientes em novas gaiolas. Repetiu-se esse procedimento até a obtenção da quarta geração (F4), sendo esta selecionada para a realização dos testes.

Como princípio ativo selecionou-se o neonicotinoide tiametoxam. A metodologia empregada para o cálculo da $\mathrm{DL}_{50}$ foi a do resíduo em papel de filtro (SHEPPARD \& HINKLE, 1987). Prepararam-se as diluições a partir de $25 ; 37,5 ; 50 ; 62,5 ; 75 ; 87,5 ; 100$; 112,$5 ; 125 ; 137,5$ e $150 \mathrm{mg}$ de tiametoxam em $5,0 \mathrm{ml}$ de acetona, com a obtenção das concentrações de 5 ; 7,$5 ; 10 ; 12,5 ; 15 ; 17,5 ; 20 ; 22,5 ; 25 ; 27,5$ e $30 \mathrm{mg} /$ $\mathrm{ml}$.

Com auxilio de micropipeta de volume fixo, 36 discos de papel-filtro foram impregnados com as diferentes concentrações. Para cada disco, empregouse um mililitro $(1,0 \mathrm{ml})$ de cada diluente, sendo três repetições para cada concentração. No grupo-controle, impregnaram-se três discos com um mililitro de acetona. Cada disco, com área de aproximadamente 63,585 $\mathrm{cm}^{2}$, foi colocado no interior de cada placa de Petri, e, após este procedimento, foram mantidos em temperatura ambiente por um período de 24 horas, para evaporação da acetona. Após esse período, retiraram-se as moscas das gaiolas com auxílio de um aspirador de pó tipo industrial, sendo posteriormente imobilizadas com dióxido de carbono para separação de machos e de fêmeas. Em cada repetição foram colocadas dez moscas, cinco fêmeas e cinco machos, nas placas de Petri com os discos impregnados e, a partir daí, deuse início ao desafio em ambiente com temperatura e umidade controladas. Os tempos de avaliação da atividade do tiametoxam foram inicialmente de dez e trinta minutos e posteriormente de uma, duas, três, 12 , 24, 36 e 48 horas.

Para o cálculo da dose letal 50 , foi utilizado o programa Analyst Soft BioStat 2007 - Statistical Analysis Program.

Para avaliar uma formulação de tiametoxam na apresentação de isca mosquicida, foram realizados dois ensaios: um em ambiente controlado e um em nível de campo, seguindo a metodologia proposta pelo Regulamento Técnico para Licenciamento e/ou Renovação de Licença de Produtos Antiparasitários de Uso Veterinário da Portaria ${ }^{\circ}$ 48, de 12 de maio de 1997 , do Ministério da Agricultura, Pecuária e Abastecimento (MAPA, 1997).
Para esses ensaios, separaram-se dois gramas de isca mosquicida com tiametoxam a $1 \%$ e dois gramas de isca sem o ativo (placebo) em placas de Petri. Cada placa foi mantida no centro de uma superfície de cor branca (cartolina), com uma área de um metro quadrado.

No teste controlado, através de imobilização por dióxido de carbono, separaram-se e acondicionaram-se duzentas moscas em recipiente provisório até o início do desafio. Em uma sala de alvenaria, com uma área de aproximadamente oito metros quadrados, devidamente telada, foram colocadas as duas superfícies de papel cartolina e, no centro dessas, uma placa com a isca, e em outra a placa com o placebo, com dois metros de distância aproximadamente entre cada placa. Em seguida, as moscas foram soltas na sala, e teve início o ensaio. A cada trinta minutos, realizou-se a contagem do número de moscas mortas na área delimitada tratada e não tratada, e em seguida procedeu-se à troca da posição das superfícies (papel cartolina) com a isca tratada e a com placebo, repetindo-se esse procedimento por quatro vezes. Durante todo o ensaio, mensuraram-se a temperatura e a umidade.

Para a avaliação da isca mosquicida em nível de campo, foi seguida a metodologia descrita anteriormente. O experimento foi realizado no período mais quente do dia, ou seja, por volta do meio-dia, no aterro sanitário situado no Município de Seropédica, RJ, com a população de moscas oriunda do local.

O cálculo da eficácia foi realizado através da seguinte fórmula: [(soma das moscas mortas na área tratada - soma das moscas mortas na área não tratada) / soma das moscas mortas na área tratada] X 100 (MAPA, 1997).

\section{RESULTADOS E DISCUSSÃO}

No teste in vitro o número de moscas - nas tomadas de tempos de dez minutos, trinta minutos, uma hora, duas horas, três horas, doze horas, 24 horas, 36 horas e 48 horas - afetadas por efeito de hiperexcitabilidade após expostas ao produto foi de 11, 56, 66, 81, 87, 98171,232 e 311, respectivamente. O número de moscas mortas nas tomadas de tempos citadas acima foi respectivamente de $0,13,18,41,53,56,79,212$, 253 de um total de 330 exemplares expostos ao produto (Tabelas 1 e 2). 
TABELA 1. Número médio de adultos de Musca domestica que apresentaram hiperexcitabilidade após o contato com tiametoxam em diferentes concentrações

\begin{tabular}{lccccccccc}
\hline \multirow{2}{*}{$\begin{array}{c}\text { Dose } \\
(\mathrm{mg} / \mathrm{ml})\end{array}$} & \multicolumn{7}{c}{ Número de moscas com hiperexcitabilidade nos tempos de avaliação após o início do desafio } \\
\cline { 2 - 9 } & 10 minutos & 30 minutos & $1 \mathrm{~h}$ & $2 \mathrm{~h}$ & $3 \mathrm{~h}$ & $12 \mathrm{~h}$ & $24 \mathrm{~h}$ & $36 \mathrm{~h}$ & $48 \mathrm{~h}$ \\
\hline 5,0 & 0 & 0 & 2 & 2 & 2 & 3 & 11 & 16 & 20 \\
7,5 & 1 & 1 & 1 & 1 & 0 & 2 & 16 & 19 & 24 \\
10,0 & 1 & 1 & 2 & 2 & 3 & 5 & 9 & 22 & 27 \\
12,5 & 0 & 2 & 2 & 4 & 6 & 6 & 14 & 20 & 25 \\
15,0 & 0 & 3 & 6 & 9 & 8 & 8 & 16 & 18 & 24 \\
17,5 & 1 & 2 & 2 & 5 & 4 & 6 & 13 & 22 & 23 \\
20,0 & 0 & 5 & 4 & 4 & 8 & 8 & 12 & 20 & 52 \\
22,5 & 0 & 4 & 4 & 6 & 8 & 9 & 17 & 26 & 26 \\
25,0 & 2 & 9 & 10 & 13 & 13 & 14 & 19 & 18 & 26 \\
27,5 & 4 & 16 & 16 & 16 & 14 & 16 & 21 & 25 & 28 \\
30,0 & 2 & 13 & 17 & 19 & 21 & 21 & 23 & 26 & 30 \\
Controle & 0 & 0 & 0 & 0 & 0 & 0 & 0 & 0 & 6 \\
Total & 11 & 56 & 66 & 81 & 87 & 98 & 171 & 232 & 311 \\
\hline
\end{tabular}

* Número total de moscas com hiperexcitabilidade, avaliando-se o total de 360 moscas

TABELA 2. Número médio de adultos de Musca domestica mortos nos diferentes tempos de avaliação no teste in vitro com o neonicotinoide tiametoxam em diferentes concentrações

\begin{tabular}{lccccccccc}
\hline \multirow{2}{*}{$\begin{array}{c}\text { Dose } \\
(\mathrm{mg} / \mathrm{ml})\end{array}$} & \multicolumn{7}{c}{ Número médio de moscas mortas nos tempos de avaliação após o início do desafio } \\
\cline { 2 - 9 } & 10 minutos & 30 minutos & $1 \mathrm{~h}$ & $2 \mathrm{~h}$ & $3 \mathrm{~h}$ & $12 \mathrm{~h}$ & $24 \mathrm{~h}$ & $36 \mathrm{~h}$ & $48 \mathrm{~h}$ \\
\hline 5,0 & 0 & 0 & 0 & 1 & 1 & 1 & 4 & 16 & 21 \\
7,5 & 0 & 0 & 0 & 1 & 1 & 1 & 5 & 19 & 22 \\
10,0 & 0 & 0 & 0 & 3 & 3 & 3 & 5 & 21 & 26 \\
12,5 & 0 & 0 & 1 & 2 & 5 & 5 & 8 & 21 & 23 \\
15,0 & 0 & 0 & 2 & 6 & 6 & 8 & 6 & 18 & 19 \\
17,5 & 0 & 1 & 1 & 4 & 4 & 4 & 5 & 18 & 19 \\
20,0 & 0 & 1 & 0 & 5 & 6 & 6 & 4 & 14 & 21 \\
22,5 & 0 & 1 & 1 & 1 & 6 & 6 & 9 & 22 & 23 \\
25,0 & 0 & 3 & 3 & 4 & 6 & 7 & 8 & 16 & 24 \\
27,5 & 0 & 4 & 5 & 5 & 5 & 5 & 13 & 23 & 27 \\
30,0 & 0 & 3 & 5 & 9 & 10 & 10 & 12 & 24 & 28 \\
Controle & 0 & 0 & 0 & 0 & 0 & 0 & 0 & 0 & 0 \\
Total & 0 & 13 & 18 & 41 & 53 & 56 & 79 & 212 & 253 \\
\hline
\end{tabular}

Número total de moscas mortas, avaliando-se um total de 360 moscas.

$\mathrm{O}$ valor encontrado para $\mathrm{DL}_{50}$ em $M$. domestica foi de $0,2612 \mathrm{mg} / \mathrm{cm}^{2}$ com intervalo de confiança (95\%) de 0,0078 a $8,7573 \mathrm{mg} / \mathrm{cm}^{2}$. Calculou-se a dose com base na tomada de tempo de 36 horas, na qual ocorreu alta taxa de mortalidade no grupo tratado. No grupo testemunha não havia nenhuma mosca morta.

KRISTENSEN \& JESPERSEN (2008), em seus experimentos, calcularam a $\mathrm{DL}_{50}$ do tiametoxam, sob 
forma de iscas, em $M$. domestica, encontrando o valor de $1,7 \mu \mathrm{g}$ em cada grama de isca utilizada. Embora, na metodologia utilizada, a forma de apresentação do produto ser diferente, cabe salientar que os resultados obtidos revelam eficácia do tiametoxan sobre $M$. domestica, corroborando os resultados encontrados no presente trabalho.

Diversos compostos inseticidas, na formulação spray, foram testados para cálculo da $\mathrm{DL}_{50}$, em uma espécie de coleóptero, Agriotres obscurus, dentre eles o neonicotinoide tiametoxam. Para este inseticida, o valor encontrado neste inseto foi de $0,17 \%$, correspondendo a $1,7 \mathrm{mg}$ em cada mililitro de produto (VANHERK et al., 2008). Apesar de se tratar de um inseto diferente, é apreciável se considerar que pertencem à mesma Classe, Insecta, portanto, apresentam fisiologia semelhante. Diante disso, assim como no presente trabalho, é mais uma vez comprovada a eficácia do tiametoxam em insetos.

No ambiente controlado, expondo duzentas moscas à isca com ativo, o total de moscas mortas foi de 38 , no período de duas horas (Tabela 3 ). No teste efetuado em campo, o número de moscas mortas foi de 254 exemplares, com registros de temperatura durante o período variando de 26 a $27^{\circ} \mathrm{C}$ e umidade relativa de $80 \%$ (Tabela 4). Observou-se que, nas posições em que as iscas ficavam em área com maior iluminação, ocorreu maior taxa de mortalidade. Trata-se de resultado que reforça a recomendação do MAPA quanto à mudança de posições entre o grupo-controle e o grupo-tratado.

A eficácia das iscas utilizadas no ambiente controlado e em campo foi respectivamente de $94,74 \% \mathrm{e}$ $98,03 \%$. A recomendação do MAPA (1997) é que a eficácia mínima seja de $80 \%$ para produtos mosquicidas.

TABELA 3. Eficácia do tiametoxam a $1 \%$ em uma formulação de isca mosquicida no controle de adultos de Musca domestica em ambiente controlado

\begin{tabular}{lcc}
\hline \multirow{2}{*}{ Tempos de avaliação } & \multicolumn{2}{c}{ Número de moscas adultas mortas } \\
\cline { 2 - 3 } & $\begin{array}{c}\text { Isca com } \\
\text { tiametoxam }\end{array}$ & Isca (placebo) \\
\hline 30 minutos & 29 & 0 \\
60 minutos & 09 & 0 \\
90 minutos & 0 & 1 \\
120 minutos & 0 & 1 \\
Total & 38 & 2 \\
Eficácia $(\%)$ & 94,74 & - \\
\hline
\end{tabular}

TABELA 4. Eficácia do tiametoxam a $1 \%$ em uma formulação de isca mosquicida no controle de adultos de Musca domestica em nível de campo

\begin{tabular}{lcc}
\hline \multirow{2}{*}{ Tempos de avaliação } & \multicolumn{2}{c}{ Número de moscas adultas mortas } \\
\cline { 2 - 3 } & $\begin{array}{c}\text { Isca com } \\
\text { tiametoxam }\end{array}$ & Isca (placebo) \\
\hline 30 minutos & 39 & 0 \\
60 minutos & 95 & 4 \\
90 minutos & 95 & 1 \\
120 minutos & 25 & 0 \\
Total & 254 & 5 \\
Eficácia (\%) & 98,03 & - \\
\hline
\end{tabular}

A precariedade das condições higiênico-sanitárias predispõe à proliferação de populações de diversos insetos, inclusive $M$. domestica. Existem poucos estudos empregando-se o tiametoxam no controle deste díptero, que tantos prejuízos provocam à saúde de homens e animais. Os resultados obtidos poderão contribuir com o sucesso do seu controle, proporcionando bem-estar e melhores condições de saúde, uma vez que as moscas são responsáveis pela veiculação de diversos patógenos.

\section{CONCLUSÃO}

A isca utilizada de tiametoxan nos ensaios foi eficaz no controle de $M$. domestica tanto em ambiente controlado quanto em nível de campo.

A determinação da $\mathrm{DL}_{50}$ para $M$. domestica, com o tiametoxam, utilizando-se papel-filtro impregnado com este composto, possibilitará o monitoramento periódico de possível desenvolvimento de focos de resistência da mosca doméstica a esta nova classe dos neonicotinoides.

\section{REFERÊNCIAS}

CHAPMAN, P. A.; WELB, D. P.; WALKER, S. J. The potential of some newer photostable pyrethroids to select for resistance in the house fly Musca domestica (Diptera: Muscidae). Bulletin of Entomological Research, v. 83, p. 517-21, 1993.

COLLOBERT-LAUGIER, C.; LAMIDEY, C.; BRISSEAU, N.; MOUSSU, C.; HAMET, N. Prevalence of stomach nematodes (Habronema spp, Draschia megastoma and Trichostrongylus axei) in horses examined post mortem in Normandy. Revue de Médecine Vétérinaire, v. 2, p. 151-156, 2000. 
FOEDAR, R. Vector of house flies (Musca domestica) in the transmission of Vibrio cholerae in India. Acta Tropica, v. 78, n. 1, p. 31-34, 2001.

FREITAS, M. O.; COSTA, H. M. A.; COSTA, J. O.; IIDE, PAULO. Entomologia e acarologia médica e veterinária. 4. ed. Belo Horizonte: Rabelo e Brasil, 1978. 253 p.

HEWITT, C. G. The house fly Musca domestica Linn: its structure, habits development relation to disease and control. Cambridge: The University Press, 1914. p. 195,

HORSFALL, M. W. Observations on the life history of Raillietina echinobothrida and of $R$. tetragona (Cestoda). The Journal of Parasitology, v. 24, n. 5, p. 409-421, 1938.

KAGABU, S. Chloronicotinyl insecticides: discovery, application and future perspective. Reviews in Toxicology, v. 1, n. 7-8, p. 75-129, 1997.

KIRIYAMA, K.; NISHIMURA, K. Structural effects of dinotefuran and analogues in insecticidal and neural activities. Pest Management Science, v. 58, p. 669-676, 2002.

KRISTENSEN, M.; JESPERSEN, J. B. Susceptibility to thiamethoxam of Musca domestica from Danish livestock farms. Pest Management Science, v. 64, n. 2, p. 126-32, 2008.

MAPA - Ministério da Agricultura, Pecuária e Abastecimento. Regulamento Técnico para Licenciamento e/ou Renovação de Licença de Produtos Antiparasitários de Uso Veterinário da Portaria n. 48, de 12 de maio de 1997. Diário Oficial da União, 16 de maio de 1977, seção 1, p. 10-165, Brasília, DF.
NAUEM, R.; EBBINGHAUS-KINTSCHER, U.; SALGADO, V. L.; KAUSSMANN, M. Thiamethoxam is a neonicotinoid precursor converted to clothianidin in insects and plants. Pesticide Biochemistry and Physiology, v. 76, n. 2, p. 55-69, 2003.

NEVES, B. P.; NOGUEIRA J. C. M. Cultivo e utilização do Nim Indiano (Azadirachta indica A. Juss). Goiânia: Embrapa-CNPAF, 1996. Goiânia, p.32.

RIBEIRO, P. B.; OLIVEIRA, C. M. B.; COSTA, P. R. P.; BRUM, J. G. W. Foréticos da Dermatobia hominis (L. Jr., 1781) (Diptera: Cuterebridae), no Rio Grande do Sul, Brasil. Arquivo Brasileiro de Medicina Veterinária e Zootecnia, v. 7, n. 5, p. 507-509, 1985.

SHEPPARD, D. C.; HINKLE, N. C. A field procedure using disposable materials to evaluate horn fly insecticide resistance. Journal of Agriculture Entomology, v. 4, n. 1, p. 87-89, 1987.

TOMIZAWA, M.; CASIDA, J. E. Selective toxicity of neonicotinoids attribuable to specificity of insect and mammalian nicotinic receptors. Annual Review of Entomology, v. 48, n. 1, p. 339-364, 2003.

VAN-HERK, W. G.; VERNON, R. S.; TOLMAN, J. H.; SAAVEDRA, H.O. Mortality of a wireworm, Agriotes obscurus (Coleoptera: Elateridae), after topical application of various insecticides. Journal of Economic Entomology, v. 101, n. 2, p. 375-383, 2008.

WAKITA, T.; YASUI, N.; YAMADA, E.; KISHI, D. Development of a novel insecticide, dinotefuran. Journal of Pesticide Science, v. 30, n. 2, p. 122-123, 2005.

Protocolado em: 13 mar. 2009. Aceito em: 15 abr. 2010. 